\section{NEW NICE GUIDANCE TO IMPROVE CHILD SEDATION STANDARDS}

The National Institute for Health and Clinical Excellence (NICE) has published a new guideline that will ensure that anxious young NHS patients do not receive ineffective or unsafe sedation drugs ahead of any therapeutic or diagnostic procedure, such as a biopsy or MRI scan, correcting a dislocated joint, or dental treatment.

Standards of practice in delivering sedation vary greatly across the country. The new guideline incorporates a series of recommendations for healthcare professionals:

- Ensuring that trained healthcare professionals carry out pre-sedation assessments and document the result in the patient's healthcare record

- Offering the child or young person (and their parents or carers) verbal and written information about the proposed sedation technique, the alternatives to sedation and associated risks and benefits

- For moderate and deep sedation, con- tinuously monitor the child or young person, ensuring that the data are clearly documented in the patient's healthcare record

- Healthcare professionals delivering sedation should have documented up to date evidence of competency and should ensure they update their knowledge and skills through programmes designed for continuing professional development (CPD).

Specific sedatives for use in dental procedures are also addressed. Dr Paul Averley, a dentist from Teeside and guideline developer, said: 'Sadly in the UK, many children continue to need invasive dental treatment. It is the responsibility of the dentist to control [the child's] anxiety. If sedation is delivered correctly within dental practice, anxious children will be less likely to be referred to hospital where their treatment would be carried out under a general anaesthetic.'

NICE has produced a number of implementation tools including a slide-set and costing report, which can be found at www.nice.org.uk/CG112.

\title{
EXPERT GLOBAL ALLIANCE TO BE FORMED
}

The Cochrane Oral Health Group (COHG) is to establish a Professional Global Alliance this year. National and international organisations working in oral health have been approached to join the Alliance, which aims to create an expert methodological and administrative team to lead the preparation of systemic reviews, with the help of international clinical experts.

The COHG is part of the Cochrane Collaboration, an international nonprofit, independent organisation, providing up to date information about the effects of healthcare by publishing high quality systematic reviews of clinical trials.

Currently COHG reviews are usually undertaken by clinicians with some limited methodological help from the editorial base. Once published, each review needs regular updating (current Cochrane guidance is every two years).

Due to increased commitments on clinicians' time and more complex research methods being introduced centrally, the COHG needs to fundamentally change the way that many of its reviews are conducted. The Group is looking for a source of funding as it is unable to accept funding from industrial or pharmaceutical companies.

In return for an annual contribution, members of the new Alliance will be consulted on the prioritisation of reviews to be undertaken, and representatives will join an Advisory Group to ensure that the oral health reviews published in The Cochrane Library are of the highest quality.

\section{DIARY}

\section{JANUARY}

Training essentials - Management of medical emergencies for the whole dental team

Date: 27 January 2011

Venue: BDA, London

Email: events@bda.org

www.bda.org/events

\section{FEBRUARY}

Tooth wear and acid erosion: modern strategies of management By Alex Milosevic

Date: 1 February 2011

Venue: The Centre for Health Science,

Raigmore Hospital, Inverness

www.bda.org/events

UAE International Dental

Conference \& Arab Dental Exhibition

Date: 1-3 February 2011

Venue: Dubai International Convention

and Exhibition Center Halls 5-8

www.aeedc.com

BDA and UCL Eastman Dental Institute:

Career opportunities in UK dentistry

Date: 4 February 2011

Venue: Hotel Russell, London

Telephone: 02079051248

Email:k.rhatigan@eastman.ucl.ac.uk

Young Dentist Conference

Date: 5 February 2011

Venue: Novotel London St Pancras, London

Email: events@dentalprotection.org

Telephone: 02073991339

www.dentalprotection.org/ydc

You and the General Dental Council

Date: 17 February 2011

Venue: Maple House, Birmingham

www.gdc-uk.org

\section{AOG/FGDP(UK)/Indian}

Dental Association conference

Date: 20 February 2011

Venue: Delhi, India

Telephone: 02077886452

and state AOG/FGDP Tour

http://aoguk.org/indian-tour.html 